\title{
KEBERADAAN BORAKS PADA MAKANAN JAJANAN DI KOTA BANJARBARU
}

\author{
M. Ilham Rusadi, Rahmawati, Erminawati \\ Jurusan Kesehatan Lingkungan Poltekkes Kemenkes Banjarmasin \\ Jl.H.M.Cokrokusumo No.1A Kota Banjarbaru \\ Email: rahma_2362@yahoo.co.id
}

\begin{abstract}
Boraks availability on food hawker at Banjarbaru city. Pentol bakso is a very popular food in Banjarbaru City. Almost all walks of life loved this dish because flavors are tasty and the prices are cheap so not surprised if traders bulb meatballs mushrooming in every area. To meet the standard that favored consumers save time and extend the bulb meatballs, many merchants are not responsible for adding chemicals that are actually prohibited from foods like boraks. This research aims to know the existence of boraks and factors which determine the presence of boraks on food hawker bulb meatballs sold around Field Murjani. The type of research used are descriptive i.e. describing the existence of boraks, level of knowledge, and merchant processing on food hawker pentol bakso sold around the field with the approach of cross sectional Murjani. The results of laboratory examination showed that all samples taken from the pentol bakso traders selling in the vicinity of the field there is no boraks Murjani. All merchants using only food additives are allowed in processing pentol bakso. It is supported most traders have a good knowledge about the food additives. The traders expected that pentol bakso still give priority to safety and security of consumers economic interests above personally by not entering the banned food additives into processed food products.
\end{abstract}

Keywords: Food snack, Boraks

\begin{abstract}
Abstrak: Keberadaan boraks pada makanan jajanan di Kota Banjarbaru. Pentol bakso merupakan makanan salah satu jajanan yang sangat populer di Kota Banjarbaru. Hampir semua lapisan masyarakat menyukai makanan ini dikarenakan rasa yang enak dan harga yang murah sehingga tidak heran jika pedagang pentol bakso menjamur di setiap daerah. Untuk memenuhi standar yang disukai konsumen dan memperpanjang masa simpan pentol bakso, banyak pedagang yang tidak bertanggung jawab menambahkan bahan-bahan kimia yang sebenarnya dilarang untuk makanan seperti boraks. Penelitian ini bertujuan untuk mengetahui keberadaan boraks dan faktor yang menentukan keberadaan boraks pada makanan jajanan pentol bakso yang dijual di Sekitar Lapangan Murjani. Jenis penelitian yang digunakan dalam penelitian ini adalah bersifat deskriptif yaitu menggambarkan keberadaan boraks, tingkat pengetahuan pedagang, dan proses pengolahan pada makanan jajanan pentol bakso yang dijual di Sekitar Lapangan Murjani dengan pendekatan cross sectional.Hasil pemeriksaan di laboratorium menunjukkan bahwa semua sampel pentol bakso yang diambil dari pedagang yang berjualan di sekitar lapangan Murjani tidak terdapat boraks. Semua pedagang hanya menggunakan Bahan Tambahan Pangan yang diperbolehkan dalam proses pengolahan pentol bakso. Hal ini didukung sebagian besar pedagang memiliki pengetahuan baik tentang bahan tambahan makanan. Para pedagang diharapkan agar tetap mengutamakan keselamatan dan keamanan konsumen diatas kepentingan ekonomi secara pribadi dengan cara tidak memasukkan bahan tambahan pangan yang dilarang kedalam produk olahan makanannya.
\end{abstract}

Kata kunci: Makanan jajanan, Boraks 


\section{PENDAHULUAN}

Makanan jajanan merupakan
makanan dan dipersiapkan atau dijual oleh pedagang kaki lima di jalanan dan di tempattempat keramaian umum lain yang langsung dimakan atau dikonsumsi tanpa pengolahan maupun persiapan lebih lanjut. Makanan jajanan juga dikenal dengan istilah junk food, fast food, dan street food. Makanan jajanan sudah menjadi bagian yang tidak terpisahkan dari kehidupan masyarakat, baik di perkotaan maupun di pedesaan. Makanan jajanan banyak sekali jenisnya dan sangat bervariasi dalam bentuk dan harga (1).

Kontaminasi yang terjadi pada makanan dan minuman dapat menyebabkan makanan tersebut menjadi media bagi suatu penyakit. Penyakit bawaan makanan merupakan salah satu permasalahan kesehatan masyarakat(2).

Berdasarkan laporan Balai Besar POM dan Balai POM di seluruh Indonesia terjadi keracunan pangan (KLB) sebanyak 153 kejadian dan 7347 di 25 Provinsi. Kejadian keracunan terbanyak di Provinsi Jawa Barat yaitu sebesar 32 kejadian (21\%), sementara untuk Provinsi Jambi, Bengkulu, Sulawesi Tengah dan Maluku masingmasing 3 kejadian (2\%). Jika ditinjau dari sumber pangannya terlihat bahwa yang menyebabkan keracunan pangan adalah makanan yang berasal dari makanan jajanan sebesar 14,4\% kejadian keracunan (3).

Pentol bakso merupakan makanan yang sangat populer di Indonesia. Hampir semua lapisan masyarakat menyukai makanan ini dikarenakan rasa yang enak dan harga yang murah sehingga tidak heran jika pedagang pentol bakso menjamur di setiap daerah. Hasil survei yang telah dilakukan Andayani(1999), menunjukkan bahwa karakteristik bakso yang disukai konsumen adalah rasanya yang gurih, agak asin, memiliki rasa daging kuat, berwarna abu-abu pucat atau muda, beraroma daging rebus serta memiliki tekstur yang empuk dan agak kenyal. Untuk memenuhi standar yang disukai konsumen dan memperpanjang masa simpan pentol bakso, banyak pedagang yang tidak bertanggung jawab menambahkan bahan-bahan kimia yang sebenarnya dilarang untuk makanan seperti boraks (4).

Sejak lama boraks disalahgunakan oleh pedagang untuk pembuatan kerupuk beras, mie, lontong, ketupat (sebagai pengeras), bakso (sebagai pengenyal dan pengawet), kecap (sebagai pengawet), bahkan pembuatan bubur ayam (sebagai pengental dan pengawet). Padahal fungsi boraks yang sebenarnya adalah digunakan dalam dunia industri nonpangan, terutama industri kertas, gelas, pengawet kayu dan keramik . Sering mengkonsumsi makanan mengandung boraks akan menyebabkan gangguan otak, hati, lemak dan ginjal. Dalam jumlah banyak, boraks dapat menyebabkan demam, anuria (tidak terbentuknya urin), koma, merangsang sistem saraf pusat, menimbulkan depresi, apatis, sianosis, tekanan darah turun, kerusakan ginjal, pingsan bahkan kematian (5)

Hasil penelitian Nurlaila (2012) dengan uji kualitatif boraks pada pentol bakso di Martapura, dari 10 sampel yang diperiksa 8 sampel (80\%) positif mengandung boraks dan 2 sampel (20\%) negatif atau tidak mengandung boraks (6). Penelitian yang serupa dilakukan oleh Kurnia dkk (2014) dengan judul" Deteksi Boraks pada Pentol dan Empek-empek yang dijual disekitar Bundaran Banjarbaru" menggunakan metode air perasan kunyit dari 14 sampel didapat hasil 11 sampel positif mengandung boraks pada makanan jajanan pentol dan 3 sampel negatif atau tidak mengandung boraks (7).

Lapangan Murjani Kota Banjarbaru merupakan tempat yang banyak dikunjungi, baik untuk anak-anak, remaja bahkan yang tua. Lapangan Murjani juga merupakan tempat favorit banyak orang karena disana bisa santai sambil menikmati makanan atau camilan yang dijual para pedagang salah satunya pentol bakso.

Tujuan penelitian yaitu mengetahui keberadaan boraks pada makanan jajanan pentol bakso di sekitar Lapangan Murjani Kota Banjarbaru dan mengetahui tingkat pengetahuan pedagang makanan jajanan pentol bakso tentang penggunaan BTP pada makanan serta mengetahui BTP yang digunakan pada proses pengolahan makanan jajanan pentol bakso. 


\section{BAHAN DAN CARA PENELITIAN}

Jenis penelitian yang digunakan dalam penelitian ini adalah bersifat deskriptif dengan pendekatan cross sectional.Penelitian dilakukan di sekitar lapangan Murjani Kota Banjarbaru Kalimantan Selatan pada bulan Februari Juni 2015. Populasi dan sampel dalam penelitian ini adalah semua pedagang pentol yang berjualan di sekitar lapangan Murjani berjumlah 48 orang. Variabel yang diteliti dalam penelitian ini meliputi karakteristik responden meliputi tingkat pendidikan dan tingkat pengetahuan tentang bahan tambahan pangan dan bahan tambahan pangan yang digunakan dalam proses pengolahan pentol bakso.

Pengumpulan data diperoleh melalui wawancara dengan menggunakan kuesioner. Pada penelitian ini juga dilakukan pemeriksaan laboratorium untuk menguji keberadaan boraks. Data yang telah terkumpul kemudian diolah secara manual, dianalisis secara deskriptif dan dibandingkan dengan teori-teori yang berhubungan dengan penelitian.

\section{HASIL DAN PEMBAHASAN}

Lapangan Murjani merupakan salah satu tempat rekreasi yang ada di Kota Banjarbaru, terletak di Jalan Panglima Batur No. 1 (Depan Balai Kota). Lapangan Murjani juga merupakan tempat olahraga joging setiap pagi minggu dan sering juga dijadikan sirkuit balapan untuk motor. Di Lapangan Murjani banyak terdapat pedagang-pedagang makanan jajanan yang berjualan setiap harinya. Makanan jajanan yang dijual antara lain : pentol goreng, otakotak, tempura, pisang keju, batagor, jagung bakar, dan pentol bakso.

Salah satu masalah keamanan pangan yang masih memerlukan pemecahan masalah yaitu penggunaan bahan tambahan pada bahan makanan untuk berbagai keperluan. Diantara beberapa bahan tambahan pangan yang sangat sering disalahgunakan salah satunya adalah zat pengawet boraks. Secara fisik, boraks adalah serbuk kristal berwarna putih, tidak berbau, larut dalam air, tetapi tidak larut dalam alkohol. Persenyawaan bisa berada dalam bentuk persenyawaan garam natrium $\left(\mathrm{Na}_{2} \mathrm{~B}_{4} \mathrm{O}_{7}\right)$ dan bentuk persenyawaan asam
$\left(\mathrm{H}_{3} \mathrm{BO}_{3}\right)$ yang banyak digunakan dalam berbagai industri nonpangan, terutama industri kertas, gelas, pengawet kayu dan keramik(5).

\section{Karakteristik responden}

Tingkat pendidikan responden pedagang pentol bakso yang berjualan di sekitar lapangan Murjani sebagian besar tingkat pendidikan responden Sekolah Menengah Pertama (SMP) (50\%).Sebagian besar lama berjualan responden 2 tahun $(37,5 \%)$.

Responden sebagian besar memiliki pengetahuan baik tentang BTP (50\%).

\section{Hasil pemeriksaan}

BTP yang digunakan pedagang dalam proses pengolahan pada Tabel 1 .

Tabel 1. BPT yang Digunakan dalam Proses Pengolahan Pentol Bakso

\begin{tabular}{clcc}
\hline No & \multicolumn{1}{c}{ Nama BTP } & $\begin{array}{c}\text { Dosis } \\
\text { (gram) }\end{array}$ & $\%$ \\
\hline 1 & Garam & $200-250$ & 100 \\
2 & vetsin & $80-100$ & 100 \\
3 & $\begin{array}{l}\text { Penyedap rasa } \\
\text { (royco) }\end{array}$ & $84-168$ & 100 \\
4 & Bawang putih & $100-150$ & 100 \\
5 & Lada/Merica & $20-40$ & 100 \\
6 & bubuk & $5-10$ & 100 \\
7 & $\begin{array}{l}\text { Poda } \\
\text { Pripolyphol (Sodium }\end{array}$ & $5-10$ & 37,5 \\
8 & $\begin{array}{l}\text { Penguat rasa } \\
\text { daging }\end{array}$ & $5-10$ & 50 \\
\hline
\end{tabular}

Pemeriksaan boraks pada makanan jajanan pentol bakso yang dilakukan di Laboratorium Kesehatan Provinsi Kalimantan Selatan diperoleh hasil negatif atau tidak mengandung boraks.

Hasil pemeriksaan ini sesuai dengan kondisi fisik dari pentol bakso yang dijual menunjukkan warnanya yang agak kecoklatan.Tidak terdapatnya boraks pada pentol bakso yang dijual sangat menguntungkan bagi konsumen, karena konsumen terhindar dari dampak negatif boraks.

Dampak sering mengkonsumsi makanan jajanan yang mengandung boraks dapat menyebabkan iritasi saluran pencernaan yang ditandai dengan sakit kepala, pusing, muntah, mual, diare, penyakit kulit yakni kemerahan pada kulit, diikuti dengan terkelupasnya kulit ari. 
Gejala lebih lanjut ditandai dengan badan terasa lemah, kerusakan ginjal, pingsan, bahkan shock dan kematian bila tertelan 5 10 gr boraks (5).

Dalam hal ini perilaku seorang pedagang atau penjual makanan jajanan pentol bakso sangat mempengaruhi kualitas makanan yang dijualnya. Menurut teori Lawrance Green dan kawan-kawan (1980) menyatakan bahwa perilaku manusia dipengaruhi oleh dua faktor pokok, yaitu faktor perilaku (behaviorcauses) dan faktor diluar perilaku (non behaviour causes). Selanjutnya perilaku itu sendiri ditentukan atau terbentuk dari 3 faktor. Salah satunya faktor predisposisi (predisposing factors) yang mencakup pengetahuan, sikap dan sebagainya (8).

Pengetahuan merupakan hasil dari tahu, dan ini terjadi setelah orang melakukan pengindraan terhadap suatu objek tertentu. Penginderaan terjadi melalui pancaindra manusia, yakni indra penglihatan, pendengaran, penciuman, rasa dan raba. Sebagian besar pengetahuan manusia diperoleh melalui mata dan telinga (8).

Berdasarkan hasil data yang didapat bahwa tingkat pengetahuan para pedagang pentol bakso yang berjualan di Sekitar Lapangan Murjani masih tergolong baik. Dari pedagang yang dijadikan responden hanya $25 \%$ yang memiliki pengetahuan kurang. Sehingga, apabila pengetahuan seseorang baik, maka perilaku yang mereka timbulkan akan baik pula sesuai dengan pengetahuan yang telah mereka dapatkan selama ini.

Berdasarkan karakteristik responden pada data tingkat pendidikan menunjukkan bahwa pedagang pentol bakso yang berjualan di sekitar lapangan Murjani memiliki tingkat pendidikan yang tergolong rendah. Hanya $25 \%$ pedagang yang menempuh pendidikan sampai SMA. Menurut Notoatmodjo (2007), pendidikan dapat mempengaruhi seseorang termasuk juga perilaku akan pola hidup terutama dalam memotivasi untuk sikap berperan serta dalam pembangunan pada umumnya, semakin tinggi pendidikan seseorang makin mudah menerima informasi (8).

Pengetahuan sangat erat hubungannya dengan pendidikan, dimana diharapkan dengan pendidikan yang tinggi maka orang tersebut akan luas pula pengetahuannya. Akan tetapi perlu ditekankan bahwa seseorang yang berpendidikan rendah tidak mutlak memiliki pengetahuan rendah. Namun seiring perkembangan teknologi informasi, pengetahuan didapatkan tidak hanya melalui pendidikan formal saja. Menurut pengakuan dari pedagang itu sendiri mendapatkan informasi tentang bahaya boraks jika dimasukkan kedalam makanan melalui media elektronik (televisi) saja. Hal ini membuktikan bahwa walaupun mereka tidak memiliki tingkat pendidikan yang tinggi, tetapi mereka memiliki pengetahuan yang cukup baik mengenai boraks.

Hasil dari penelitian ini sejalan dengan hasil penelitian yang dilakukan oleh Nurlaila (2012) yang menyatakan bahwa ada atau terdapat hubungan antara pengetahuan pedagang makanan jajanan terhadap penggunaan boraks pada pentol bakso (6).

Pentol bakso yang dijual di lapangan Murjani dapat bertahan lama karena dari segi komposisi pentol bakso dan cara perlakuannya. Dari segi komposisi pedagang hanya menggunakan bahan tambahan pangan yang diperperbolehkan dalam proses pengolahan pentol bakso dan penggunaan bawang putih pada pentol bakso tidak hanya berfungsi sebagai penyedap rasa tetapi juga berfungsi sebagai pengawet alami.Dari segi perlakuan pentol bakso yang dijual selalu dalam keadaan hangat pada saat penjualan dan sisa dari bakso yang tidak terjual disimpan di dalam kulkas.

Tidak ditemukannya boraks pada pentol bakso yang dijual di Sekitar Lapangan Murjani dapat juga disebabkan karena adanya pengawasan yang dilakukan oleh Dinas Kesehatan Kota Banjarbaru kepada pedagang makanan jajanan yang berjualan di lapangan Murjani.

\section{KESIMPULAN DAN SARAN}

Tidak ditemukan keberadaan boraks pada makanan jajanan pentol bakso yang dijual di sekitar lapangan Murjani.Tingkat pengetahuan pedagang tentang BTP sebanyak 50\% memiliki pengetahuan baik, $25 \%$ masing-masing memiliki pengetahuan 
cukup dan kurang.Bahan tambahan pangan yang digunakan pedagang dalam proses pengolahan pentol bakso adalah bahan tambahan pangan yang diperbolehkan yaitu garam, vetsin, penyedap rasa (royco), bawang putih, lada/merica bubuk, soda, pengenyal (sodium tripolyphosphat) dan penguat rasa daging.

Saran yang dapat diberikan kepada Dinas Kesehatan Kota Banjarbaru untuk memberikan penyuluhan kepada pedagang makanan jajanan khususnya pedagang pentol bakso mengenai cara pengolahan makanan yang baik.Kepada para pedagang pentol bakso agar tetap mengutamakan keselamatan dan keamanan konsumen diatas kepentingan ekonomi secara pribadi dengan cara tidak memasukkan BTP yang dilarang kedalam produk olahan makanannya.Meskipun tidak ditemukan penyalahgunaan boraks pada makanan jajanan pentol bakso tetapi pemerintah harus tetap melakukan pengawasan yang lebih ketat terhadap keamanan makanan jajanan di Wilayah Kota Banjarbaru khususnya di lapangan Murjani.

\section{KEPUSTAKAAN}

1. Amir, Sakinah, 2014.Analisis Kandungan Boraks pada Pangan Jajanan anakdi SDN Kompleks Lariangbangi Kota Makassar, Universitas Hasanuddin, Makassar.

2. WHO, 2006. Penyakit Bawaan Makanan: Fokus Pendidikan Kesehatan, Kedokteran EGC, Jakarta.

3. BPOM RI, 2011. Kejadian Luar Biasa Keracunan Pangan, http://docs,google.com/viewer, diakses 10 Februari 2015.

4. Andayani, R. Y, 1999. Standarisasi Mutu Bakso Sapi Berdasarkan Kesukaan Konsumen Studi Kasus Bakso di Wilayah DKI Jakarta, Institut Pertanian Bogor, Bogor.

5. Wijaya, Desy, 2011. Waspadai Zat Aditif dalam Makananmu. Buku Biru, Yogyakarta.

6. Nurlaila, 2012. Hubungan Pengetahuan Pedagang Makanan Jajanan Terhadap
Penggunaan Boraks pada Pentol Bakso yang Dijual di Lingkungan SDN Jawa dan SDN Keraton di Martapura 2012, Karya Tulis Ilmiah, Poltekkes Kemenkes Banjarmasin, Banjarmasin.

7. Kurnia, S, dkk, 2014. Deteksi Boraks pada Pentol dan Empek-Empek yang Dijual di Sekitar Bundaran Simpang Empat Kota Banjarbaru, Karya Tulis Ilmiah, Poltekkes Kemenkes Banjarmasin, Banjarmasin.

8. Notoatmodjo, Soekidjo, 2007. Pendidikan dan Perilaku Kesehatan, Rineka Cipta, Jakarta. 